\title{
云南金满热液脉状铜矿床 $\mathrm{Cu}$ 同位素组成的初步测定
}

\author{
蒋少涌 ${ }^{\mathbb{1}}$ J. Woodhead ${ }^{(2)}$ 于际民融家永 $^{(1)}$ 廖启林 ${ }^{\mathbb{1}}$ 吴南平 ${ }^{(1)}$
}

(1)南京大学地球科学系成矿作用国家重点实验室, 南京 210093; (2)School of Earth Sciences, Melbourne University, Vic 3010, Australia. E-mail: shyjiang@public1.ptt.js.cn)

摘要 报道产于兰坪一思茅盆地中侏罗系沉积砂岩、泥岩中的金满低温热液脉状铜矿床中含 $\mathrm{Cu}$ 硫化物 的 $\mathrm{Cu}$ 同位素组成, 发现其 $\delta^{65} \mathrm{Cu}$ 值较低, 变化范围为 $-3.70 \%$ 0.30\% , 明显不同于高温岩浆热液铜矿 床 $\left(\delta^{65} \mathrm{Cu}\right.$ 值为- $0.62 \%$ 0.40\% $)$ 和大洋底块状硫化物矿床 $\left(\delta^{65} \mathrm{Cu}\right.$ 值为 $-0.48 \%$ 1.15\%o). 根据研究结果 认为: 较低的成矿温度、不同的成矿物质来源、不同的成矿阶段和有机质参入成矿等因素, 可能是造成 金满型低温热液脉状铜矿床 $\mathrm{Cu}$ 同位素分馏的原因.

\section{关键词 $\mathrm{Cu}$ 同位素 含 $\mathrm{Cu}$ 矿物 热液脉状矿床 云南金满}

$\mathrm{Cu}$ 同位素地球化学是国际上刚刚发展起来的一 种新的稳定同位素方法. 虽然早在 20 世纪 50 及 60 年代, 就有人开展过自然界中 $\mathrm{Cu}$ 同位素组成的测 定 $^{[1,2]}$, 但由于当时分析测试手段的落后, 测定的 $\mathrm{Cu}$ 同位素组成与分析方法的误差在同一个数量级 (1\%o 2\%o), 因而无法发现自然界中 $\mathrm{Cu}$ 同位素组成的 变化. 最近几年来, 由于新一代的多接收等离子体质 谱仪(MC-ICPMS)在同位素地球化学中的应用, 使得 像 $\mathrm{Cu}, \mathrm{Zn}, \mathrm{Fe}, \mathrm{Hf}, \mathrm{W}$ 等这样一些十分难电离的、难于 用传统的热电离质谱测量的元素的同位素的高精度 测量成为现实 ${ }^{[3,4]}$. 目前, 国外已有几家实验室开始 了 $\mathrm{Cu}$ 同位素的研究, 化学和质谱分析测量方法已经 成熟, 并发现了 $\mathrm{Cu}$ 同位素在自然界中变化的一些规 律 ${ }^{[5,6]}$. 为了进一步弄清 $\mathrm{Cu}$ 同位素在自然界中的组成 和变化规律, 特别是能否将 $\mathrm{Cu}$ 同位素作为一种有效 的地球化学示踪剂用于研究含 $\mathrm{Cu}$ 金属硫化物矿床的 成矿物质来源、形成机理和矿床成因, 我们开展了热 液脉状铜矿床的 $\mathrm{Cu}$ 同位素研究. 本文报道了我国云 南金满热液脉状铜矿床的 $\mathrm{Cu}$ 同位素分析初步成果.

\section{1 矿床地质概况}

金满热液脉状铜矿床, 位于云南兰坪-思茅盆地 的西北边缘, 澜沧江断裂的东侧. 兰坪-思茅盆地地 处欧亚板块与印度板块的拼接带, 是在海西期基底 上发育起来的中新生代陆相裂谷沉积盆地. 该盆地内 储藏有十分丰富的矿产资源, 并发现了一系列的脉状 富铜矿床和矿化点. 金满铜矿是其中最具规模、最典型 的、且研究程度最高的一个矿床 ${ }^{[7-9]}$.

矿区出露的地层主要为三叠系至第三纪, 赋矿
地层为中侏罗纪花开佐组 $\left(\mathrm{J}_{2} \mathrm{~h}\right)$ 的紫红色砾岩、长石石 英砂岩、含碳钙质板岩和绢云母板岩、局部夹膏盐层. 矿化明显受断层破碎带控制, 矿体主要以大脉状产 于 NNE 走向、NWW 倾向, 倾角 $15 \sim 70^{\circ}$, 沿倾角断 层的破碎带中(图 1), 矿体厚度变化大, 最小 $1.2 \mathrm{~m}$, 最大 $14.6 \mathrm{~m}$, 平均 $8.1 \mathrm{~m}$. 矿区内各类岩石的䢃理十 分发育, 在赋矿的泥质板岩和砂岩的裂隙和嬖理中 常可见浸染状或细脉状分布的石英-方解石-硫化物 脉，富集时可构成细脉型矿体.

矿石矿物以砷墨铜矿、黝铜矿、斑铜矿和黄铜矿

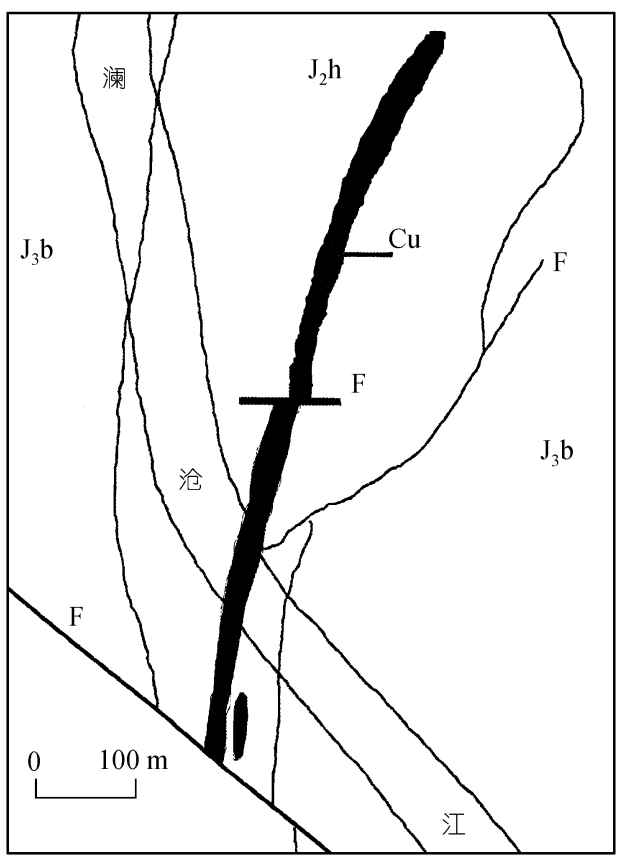

图 1 金满铜矿地质略图

$\mathrm{J}_{2} \mathrm{~h}$ : 中侏罗统花开佐组; $\mathrm{J}_{3} \mathrm{~b}$; 中侏罗坝注路组; F: 断层; $\mathrm{Cu}$ : 铜矿体 
为主, 也见少量黄铁矿、毒砂、辉铜矿、硫钴矿、方 铅矿、闪锌矿和自然银. 脉石矿物以石英和方解石为 主, 也见铁白云石、菱铁矿、重晶石、绢云母和绿泥 石. 围岩蚀变以硅化为主, 表现为赋矿岩石的褪色蚀 变和石英脉体沿层理或裂隙充填交代.

\section{$2 \mathrm{Cu}$ 同位素分析方法}

本次分析所用样品为黄铜矿和砷䵢铜矿. 样品 经手工和显微镜下挑纯后, 取约 $2 \mathrm{mg}$ 用 $1 \mathrm{~mL}$ 王水溶 解, 放在近于 $80^{\circ} \mathrm{C}$ 电热板上过夜, 样液蒸干后用 $7 \mathrm{~mol} / \mathrm{L} \mathrm{HCl}+0.001 \% \mathrm{H}_{2} \mathrm{O}_{2}$ 提取, 通过 AG MP-1 阴 离子交换树脂(100 200 目, 氯离子型)进一步纯化 ${ }^{[5]}$, 获得纯的含 $\mathrm{Cu}$ 试样, 用于质谱分析.

$\mathrm{Cu}$ 同位素的质谱分析是在澳大利亚墨尔本大学 的同位素实验室完成的. 分析所用的仪器为墨尔本 大学 1999 年购置的专门用于同位素分析的 $\mathrm{Nu}$ Instrument 型多接收等离子体质谱仪(MC-ICPMS). 该仪器具有高灵敏度、高精度和多接收器同时测定不 同同位素等优点, 是目前国际上用于 $\mathrm{Cu}$ 同位素测试 的最好仪器.

测量过程中, 我们采用美国国家标准局的 NIST $976 \mathrm{Cu}$ 同位素标样作为实验室标准. 采用标准匹配 法(即 1 个标样, 1 个样品交替测量)来进行仪器质量歧 视和同位素分馏校正.

同位素分析结果采用 $\delta^{65} \mathrm{Cu}$ 表示:

$$
\delta^{65} \mathrm{Cu}=\left[\frac{\left({ }^{65} \mathrm{Cu} /{ }^{63} \mathrm{Cu}\right)_{\text {样品 }}}{\left({ }^{65} \mathrm{Cu} /{ }^{63} \mathrm{Cu}\right)_{\text {标准 }}}-1\right] \times 1000,
$$

所用标准 NIST 976 的 ${ }^{65} \mathrm{Cu} /{ }^{63} \mathrm{Cu}$ 比值为 0.4464 . 样品分析测试精度优于 $0.05 \%$.

\section{3 分析结果及讨论}

金满铜矿床 $\mathrm{Cu}$ 同位素分析结果见表 1 , 其中大
脉状矿体中一个黄铜矿的 $\delta^{65} \mathrm{Cu}$ 值为 $0.30 \%$, 一个砷 黝铜矿的 $\delta^{65} \mathrm{Cu}$ 值为 $-1.62 \%$. 一个碳质泥岩中细脉 状黄铜矿的 $\delta{ }^{65} \mathrm{Cu}$ 值为-3.62\% - 3.70\% , 大大低于大 脉状矿体中的 $\delta^{65} \mathrm{Cu}$ 值. 一个采自兰坪盆地白秧坪铜 银多金属矿床中的脉状黝铜矿具有与金满砷䵢铜矿 相近的 $\delta^{65} \mathrm{Cu}$ 值 $(-1.32 \%$ ) .

由于 $\mathrm{Cu}$ 同位素的分析研究工作还刚刚起步, 积 累的数据有限. Marechal 等人 ${ }^{[5]}$ 首次分析了采自世界 各地的 7 个含铜矿物, 发现了十分大的 $\mathrm{Cu}$ 同位素组 成变化 $\left(\delta^{65} \mathrm{Cu}=-3.03 \%\right.$ $5.74 \%$ ) , 其中最低值为一 个自然铜样品, 最高值为一个黄铜矿样品. 由于他们 所分析的样品地质情况不清楚, 无法进行对比和进 一步分析其地质意义. 尽管如此, Marechal 等人的工 作至少证明了含铜矿物间可能存在十分大的同位素 分馏, 因而有可能将 $\mathrm{Cu}$ 同位素作为一种灵敏的地球 化学示踪剂应用到解决实际地质问题中.

Zhu 等人 ${ }^{[6]}$ 对某些与岩浆岩有关的高温热液铜矿 床和现代大洋底块状硫化物矿床的 $\mathrm{Cu}$ 同位素组成进行 了初步分析. 他们发现英国 Cornwall, 南非 Bushveld 和 芬兰 Outokumpo 等地与岩浆岩有关的高温热液黄铜矿 具有十分窄的 $\delta^{65} \mathrm{Cu}$ 值变化 $(-0.23 \%$ 0.13\%o). 加拿 大 Sudbury $\mathrm{Cu}-\mathrm{Ni}$ 硫化物矿床中黄铜矿的 $\delta^{65} \mathrm{Cu}$ 值变 化稍大, 为 $-0.62 \%$ $0.40 \%$ 。 现代大洋底块状硫化物 的 $\delta^{65} \mathrm{Cu}$ 值变化为 $-0.48 \%$ 1.15\%o, 变化范围不但大 于岩浆热液矿床, 而且更加富集 ${ }^{65} \mathrm{Cu}$.

金满铜矿床的 $\delta^{65} \mathrm{Cu}$ 值明显不同于岩浆热液铜 矿床和现代大洋底块状硫化物矿床(图 2). 金满铜矿 床低的 $\delta^{65} \mathrm{Cu}$ 值可能与下列因素有关:

( i ) 较低的成矿温度. 流体包裹体研究表明, 金满铜矿床的形成温度较低, 并可分为两组, 一组为 $150 \sim 202^{\circ} \mathrm{C}$, 含盐度 $w(\mathrm{NaCl})$ 为 $8.6 \% \sim 10.7 \%$; 另一组为 $260 \sim 286^{\circ} \mathrm{C}$, 含盐度 $w(\mathrm{NaCl})$ 为 $13.2 \% \sim 14.4 \%$, 反映了

表 1 金满热液脉状铜矿床的 $\mathrm{Cu}$ 同位素组成与高温岩浆热液铜矿床和大洋底块状硫化物矿床的 $\mathrm{Cu}$ 同位素结果比较

\begin{tabular}{|c|c|c|c|c|}
\hline 样号 & 测试矿物 & $\delta^{65} \mathrm{Cu} / \%$ o & 样品地质情况 & 备注 \\
\hline JM-4 & 黄铜矿 & +0.30 & 金满黄铜矿-石英脉 & 本文 \\
\hline JM-12 & 砷黝铜矿 & -1.62 & 金满黝铜矿-石英脉 & 本文 \\
\hline JM-23(1) & 黄铜矿 & -3.62 & 金满碳质泥质中细脉状黄铜矿 & 本文 \\
\hline JM-23(2) & 黄铜矿 & -3.70 & 金满碳质泥质中细脉状黄铜矿 & 本文 \\
\hline HX-81 & 砷䵢铜矿 & -1.32 & 白秧坪方解石脉中砷黝铜矿 & 本文 \\
\hline $5^{\text {a) }}$ & 黄铜矿 & $-0.23 \sim+0.13$ & 与岩浆岩有关的高温热液黄铜矿 & 文献[6] \\
\hline $6^{\text {a) }}$ & 黄铜矿 & $-0.62 \sim+0.40$ & Sudbury 铜镍硫化物矿床 & 文献[6] \\
\hline $22^{\text {a) }}$ & 黄铜矿 & $-0.48 \sim+1.15$ & 现代大洋底块状硫化物矿床 & 文献[6] \\
\hline
\end{tabular}

a) 代表分析的样品数

https://engine.scichina.com/doi/10.1360/csb2001-46-17-1468 

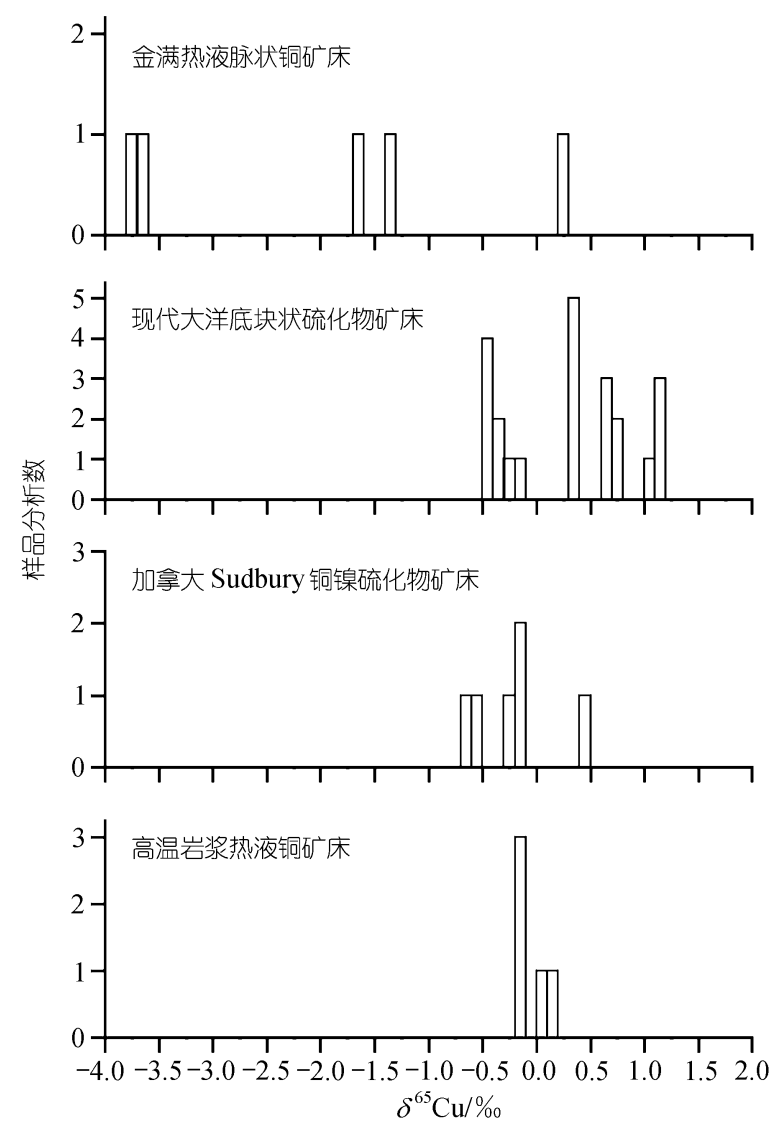

图 2 金满热液脉状铜矿床与高温岩浆热液及块状硫化物 矿床的铜同位素组成对比

两个不同成矿阶段的成矿作用 ${ }^{[9]}$. 在较低的温度下, 从热水溶液中沉淀含铜硫化物可能会造成较大的 $\mathrm{Cu}$ 同位素分馏 ${ }^{[6]}$. 碳质泥岩中细脉状黄铜矿的 $\delta^{65} \mathrm{Cu}$ 值 $(-3.62 \%$ - 3.70\%o) 明显低于大脉状矿体中黄铜矿和 砷䵢铜矿的 $\delta^{65} \mathrm{Cu}$ 值(-1.62\%o 0.30\%o), 也可能反映 了它们是在不同温度条件下从热水溶液中沉淀出来的. 但是, 有关 $\mathrm{Cu}$ 同位素的分馏机理实验研究还没有开展, 我们还无法进一步回答为什么温度降低, $\mathrm{Cu}$ 同位素分 馏加大, 硫化物会更加富集 ${ }^{63} \mathrm{Cu}$. Zhu 等人 ${ }^{[6]}$ 发现在低 温表生阶段形成的自然铜, 孔雀石 $\left[\mathrm{Cu}_{2}(\mathrm{OH})_{2} \mathrm{CO}_{3}\right]$ 和铜 兰 $\left[\mathrm{Cu}(\mathrm{OH})_{2}\left(\mathrm{CO}_{3}\right)_{2}\right]$ 具有明显较大的 $\delta^{65} \mathrm{Cu}$ 值变化范围 $(-0.33 \%$ 1.25\%o), 且比高温岩浆热液阶段形成的黄铜 矿 $\left(\delta^{65} \mathrm{Cu}=-0.23 \%\right.$ $0.13 \%$ o $)$ 更富 ${ }^{65} \mathrm{Cu}$. 但他们没有测 定过低温热液形成的黄铜矿的 $\mathrm{Cu}$ 同位素组成.

(ii) 不同的成矿物质来源. 金满铜矿床具有较 负的 $\delta^{65} \mathrm{Cu}$ 值, 可能反映了成矿物质来源不同于岩浆 热液铜矿和块状硫化物矿床. Zhu 等人 ${ }^{[6]}$ 研究的这两 类铜矿床, 前者的 $\mathrm{Cu}$ 来源于地幔岩或花岗岩, 后者
由于产出于无沉积物覆盖的大洋中脊, $\mathrm{Cu}$ 可能是海 底热水溶液从地幔玄武岩中淋滤出来的 ${ }^{[6,10,11]}$, 而金 满铜矿床中的 $\mathrm{Cu}$ 很可能是来源于热水溶液淋滤萃取 盆地沉积岩中的 $\mathrm{Cu}$. 因此, 这三类矿床具有不同的 $\delta^{65} \mathrm{Cu}$ 值, 以 $\mathrm{Cu}$ 来自沉积岩中的金满矿床的 $\delta^{65} \mathrm{Cu}$ 值最低.

（iii）不同的成矿阶段. Zhu 等人 ${ }^{[6]}$ 发现现代大 洋底同一热液硫化物烟图的不同部位 $\delta^{65} \mathrm{Cu}$ 值不同, 形成较早的底部 $\delta^{65} \mathrm{Cu}$ 值较高, 而顶部 $\delta^{65} \mathrm{Cu}$ 值降低. 因此, Zhu 等人 ${ }^{[6]}$ 提出了一个两阶段模式来解释这一 现象, 认为形成早期硫化物的成矿溶液可能优先获 取了源岩中的 ${ }^{65} \mathrm{Cu}$ ，因而使得沉淀的硫化物具有较 高的 ${ }^{65} \mathrm{Cu}$ 值, 而晚期阶段的硫化物形成于 ${ }^{65} \mathrm{Cu}$ 相对 贫化的成矿溶液. 结合金满铜矿床的具体情况, 如果 大脉状矿体形成较早, 则从中沉淀的硫化物具有较 高的 $\delta^{65} \mathrm{Cu}$ 值，相对贫 ${ }^{65} \mathrm{Cu}$ 的残余溶液进一步流向周 围地层岩石中, 因而有可能在泥质板岩的裂隙中沉 淀出 $\delta^{65} \mathrm{Cu}$ 降低的硫化物.

(iv) 有机质的影响. 金满铜矿床脉状矿体和赋 矿围岩中均含有十分高的有机碳, 可见少量碳沥青 和石墨. 对矿床中石英脉的包裹体成分同位素分析 表明, 包裹体中气体组分含有 $\mathrm{CO}_{2}$ 和 $\mathrm{CH}_{4}$, 其中 $\mathrm{CO}_{2}$ 的 $\delta{ }^{13} \mathrm{C}$ 值为 $-3.1 \%$ - $10.8 \%, \mathrm{CH}_{4}$ 的 $\delta{ }^{13} \mathrm{C}$ 值为 $-22.2 \%$ - $32.1 \% \%^{[12]}$. 说明成矿作用过程中, 有机质 的作用不容忽视. 国际上已有人开展过细菌和有机 质对 $\mathrm{Fe}$ 同位素分馏的影响, 发现 $\mathrm{Fe}$ 同位素分馏与细 菌活动关系密切 ${ }^{[13]}$. 但是, $\mathrm{Cu}$ 同位素分馏是否受细 菌和有机质的影响还需要实验的进一步证实.

\section{4 结论}

对云南金满低温热液脉状铜矿床的 $\mathrm{Cu}$ 同位素分 析结果表明, 该矿床具有十分大的 $\delta^{65} \mathrm{Cu}$ 值变化范围, 为 $-3.70 \%$ $0.30 \%$, 与高温岩浆热液铜矿床和块状硫 化物矿床相比, 金满铜矿床具有明显较负的 $\delta^{65} \mathrm{Cu}$ 值. 分析结果表明, 较低的成矿温度, 不同的成矿物质来 源，不同的成矿阶段和有机质参人成矿等因素可能 是造成金满铜矿床 $\mathrm{Cu}$ 同位素分馏和其十分特征的低 $\delta^{65} \mathrm{Cu}$ 组成的主要原因.

本文的研究表明, 含铜矿物的 $\mathrm{Cu}$ 同位素组成有 可能作为一种灵敏的地球化学示踪剂, 来指示成矿 物质来源、成矿作用过程和矿床形成机理.

致谢 0 / 和全作受国家重点基础研究发展规划项目(编号: 
G1999043208)和国家杰出青年科学基金(批准号：49925306) 资助。

\section{参考文献}

1 Walker E C, Cuttittla F, Senftle F E. Some natural variations in the relative abundance of isotopes. Geochim Cosmochim Acta, 1958, 15: $183 \sim 194$

2 Shields W R, Goldich S S, Gamer E L, et al. Natural variations in the abundance ratio and atomic weight of copper. J Geophys Res, 1965, 70(2): 479 491

3 Walder A J, Freedman P A. Isotope ratio measurements using a double focusing magnetic sector mass analyzer with an inductively coupled plasma ion source. J Anal At Spectrom, 1992, 7: 571

4 Halliday A N, Lee D C, Christensen J N, et al. Recent developments in inductively coupled plasma magnetic sector multiple collector mass spectrometry. Int J Mass Spec Ion Proc, 1995, (146-147): 21 33

5 Marechal C N, Telouk P, Albarede F. Precise analysis of copper and zinc isotopic compositions by plasma-source mass spectrometry. Chem Geol, 1999, 156: 251 273

6 Zhu X K, O’Nions R K, Guo Y, et al. Determination of natural $\mathrm{Cu}$-isotope variation by plasma-source mass spectrometry: Implications for use as geochemical tracers. Chem Geol, 2000, 16: 139 149
7 甫为民. 兰坪金满铜矿床成矿地质特征及成因探讨. 云南地质, 1992, 11(1): 63 67

8 颜文, 李朝阳. 一种新类型铜矿床的地球化学特征及其热水沉 积成因. 地球化学, 1997, 26(1): 54 63

9 阙梅英, 程敦模, 张立生, 等. 兰坪-思茅盆地铜矿床. 北京: 地 质出版社, 1998. 109

10 Seewald J S, Seyfried W E Jr. The effect of temperature on metal mobility in subseafloor hydrothermal systems: constrains from basalt alteration experiments. Earth Planet Sci Lett, 1990, 101: 388 403

11 Seyfried W E Jr, Ding K. The effect of redox on the relative solubilities of copper and iron in Cl-bearing aqueous fluids at elevated temperatures and pressures: An experimental study with application to subseafloor hydrothermal systems. Geochim Cosmochim Acta, 1993, 57: 1905 1917

12 肖荣阁. 云南中新生代地质与矿产. 北京: 海洋出版社, 1993. 204

13 Madernack K W, Bazylinski D A, Shanks W C, et al. Oxygen and iron isotope studies of magnetite produced by magentotactic bacteria. Science, 1999, 285: 1892 1896

(2001-03-30 收稿, 2001-06-17 收修改稿) 